\title{
ASO Visual Abstract: Technical Standards for Cancer Surgery- Improving Patient Care through Synoptic Operative Reporting
}

Tina J. Hieken, MD, FACS ${ }^{1}$, William R. Burns, MD, FACS ${ }^{2}$, Amanda B. Francescatti, MS ${ }^{3}$, Arden M. Morris, MD, MPH, FACS ${ }^{4}$, Sandra L. Wong, MD, MS, FACS ${ }^{5}$, and on behalf of the Cancer Surgery Standards Program of the American College of Surgeons

${ }^{1}$ Department of Surgery, Mayo Clinic, Mayo Clinic Alix School of Medicine, Rochester, MN; ${ }^{2}$ Department of Surgery, Johns Hopkins University School of Medicine, Baltimore, MD; ${ }^{3}$ American College of Surgeons, Chicago, IL; ${ }^{4}$ Department of Surgery, Stanford University School of Medicine, Stanford, CA; ${ }^{5}$ Department of Surgery, The Geisel School of Medicine at Dartmouth, Dartmouth-Hitchcock Medical Center, Lebanon, NH

The Operative Standards for Cancer Surgery manuals define critical elements of optimal cancer surgery based on data and expert opinion. Following these surgical standards and employing synoptic operative reporting may elevate and harmonize cancer patient care (https://doi.org/10.1245/ s10434-022-11330-9).

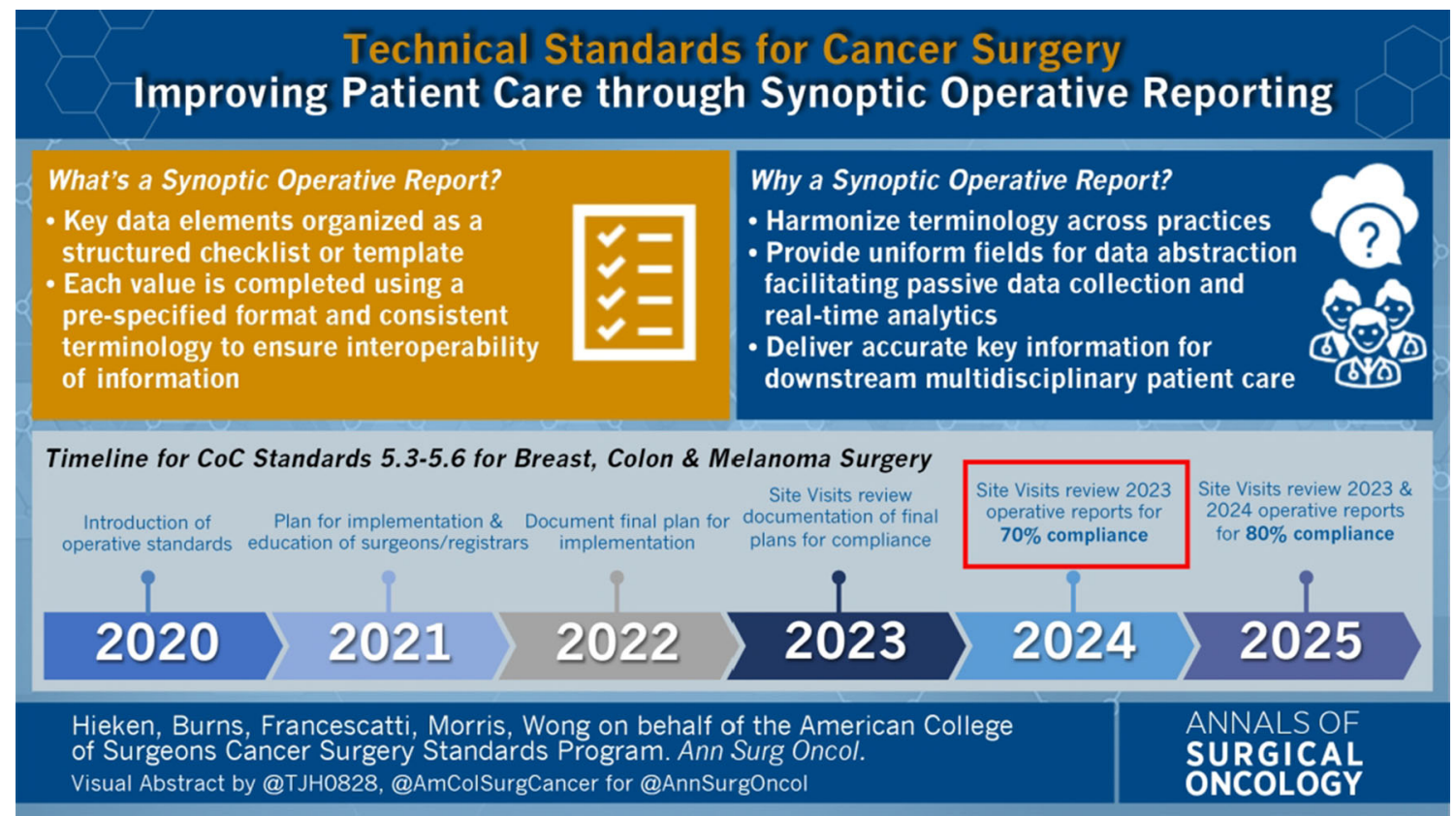

(C) Society of Surgical Oncology 2022

Published Online: 29 January 2022

T. J. Hieken, MD, FACS

e-mail: hieken.tina@mayo.edu
DISCLOSURES The authors have no relevant financial disclosures related to this work.

Publisher's Note Springer Nature remains neutral with regard to jurisdictional claims in published maps and institutional affiliations. 